\title{
The Virtual Education during the COVID-19 Pandemic Era (Empirical Evidence on Student's Online Experience)
}

\author{
Khairi Mohamed Omar \\ Business Administration Department, College of Administrative Sciences, Applied Science University, East Al-Ekir, \\ Kingdom of Bahrain \\ Email: khairi.omar@asu.edu.bh
}

How to cite this paper: Omar, K. M. (2021). The Virtual Education during the COVID-19 Pandemic Era (Empirical Evidence on Student's Online Experience). Creative Education, 12, 2959-2971. https://doi.org/10.4236/ce.2021.1212222

Received: November 24, 2021

Accepted: December 28, 2021

Published: December 31, 2021

Copyright (๑) 2021 by author(s) and Scientific Research Publishing Inc. This work is licensed under the Creative Commons Attribution International License (CC BY 4.0).

http://creativecommons.org/licenses/by/4.0/

(c) (i) Open Access

\begin{abstract}
This paper aimed to shad the light on the student's online experience during the COVID-19 pandemic. The coercitif of current situation by the unexpected circumstances caused by COVID-19 has led the universities around the globe to come up with an urgent solution and ideas to overcome those effected aspects of teaching and learning. Many universities have been compelled to close their doors and focus their efforts on online learning. Many universities has been forced to shut down the entire university and shifted onto online educational activities. The study targeted universities students in different university in Bahrain. To fulfill the study's objectives, quantitative method was applied in this study. The major instrument for the study was a questionnaire, which was utilized to obtain the desired sample size. The study used Smart PLS to analyze the gathered data. The study findings reported that students' online experience on virtual education during the COVID-19 pandemic era seems to be different from physical learning; the majority of them believe that learning is better in physical classrooms than through online education. More engagements from the relevant authorities by put in place more legislation and strict regulations in order to ensure the process and the effectiveness of virtual education.
\end{abstract}

\section{Keywords}

COVID-19, Physical Classrooms, Technology Issues, Virtual Education, Teaching and Assessment

\section{Introduction}

The pandemic outbreak coronavirus illness has resulted in an immense quantity 
of data and information being produced in a relatively short period of time relating to the various impacted and affected sectors (COVID-19). This virus, which was first detected in China in December (2019), has touched every element of human life, socially, economically, and politically.

As one of the preventive steps suggested by the World Health Organization, governments throughout the world have urged citizens to stay a safe distance (social distancing). As a result, all gatherings, even family gatherings, are in some way prohibited. As a result, colleges have been compelled to lock doors, prohibit students and staff from attending, and transfer all educational activities to virtual activities (Bao, 2020; Gandhi et al., 2020).

As a result, for the vast majority of sectors, distant contact via cyberspace was the best and only option. Institutions can utilize a variety of blended learning strategies, the most frequent of which is conventional face-to-face education. The Massive Open Online Courses (MOOCs) are one example of how technology is altering education and training delivery, and the MOOC model is gaining traction as a method to provide emerging countries with much-needed access to higher education and workforce skills training. In fact, blending content delivery medium or pedagogies is widespread in both distance and face-to-face learning (Graham, 2013). Several authors have written about the issue of online class time (Graham, 2013). However, also the pandemic offers chance for our scientific community investigating technology-related behavior to help the global effort to combat and ultimately defeat the current epidemic (Yan, 2020).

\section{Study Objectives}

This study aims to provide an empirical evidence on student's online experience on the virtual education during the COVID-19 pandemic era by reaching the following main study objective which is:

To what extent the general issues, content delivery, students' interaction and assessment and health issues effect on the students learning.

\section{Review of Literature}

There has been a lot of advances in educational technology in the last few decades and the same proved to be immensely useful during this pandemic (Chatterjee \& Chakraborty, 2020; Dhawan, 2020). Educational technology become very promising and attractive in many ways, the system of educational technology has been developed rapidly, frequently and fercuantlly. In its diverse types and forms educational technology is shown its fruits in many, it is noticeable that the educational technology has been more advances in the last few decades and the same proved to be immensely useful during this pandemic (Chatterjee \& Chakraborty, 2020; Dhawan, 2020).

Organizations need to increasingly focus on value creation and customer interaction modification by means of the strategic use of augmented reality and virtual reality. It is become significant to study and investigate value creation 
strategies for all of their stakeholders and internal influencers and other related parties. It is indeed that organizations will not contribute genuine value until they consider the context of employing VR technology (de Regt et al., 2020).

There are several online platforms has been created in very short period of time in order to support online educators (Nash, 2020). Although of all of these efforts, the universities around the globe faced a really challenge to map their educational activities in an online space during the COVID-19 outbreak. The logistic, technical, financial, and social obstacles were serious matters to be solved. Crises management committees were reformulated to overcome such issues. This took from a wide range of universities quote period of time to find out the suitable solutions which can fit to all involved bodies professors, students and staffs as well. As results, many organizations have been forced to suddenly modify their workflow strategies and adopt new technologies. Although of the limited time, they in somehow managed to reflect upon how the new strategies and the associated technologies should be introduced and integrated to their existing setup (Carroll \& Conboy, 2020). In most cases, these organizations did not get enough time to reflect upon how the new strategies and the associated technologies should be introduced and integrated to their existing setup (Carroll \& Conboy, 2020) the movement from classroom-based education toward online education because of the raging pandemic was the big argument and discussion in majority of universities around the world were no exception on that only for those providing online education (Distance learning) as applied system. Several attempts towards understanding the students view and opinion has been conducted in different environment, (Mishra, Gupta, \& Shree, 2020; Aguilera-Hermida, 2020; Bojovic, Bojovic, Vujosevic, \& Suh, 2020).

The lookdowns caused by COVID-19 pandemic has affected people in different aspects of life such as stress and anxiety or in general the mental health issues (Cao et al., 2020; Islam, Barna, Raihan, Khan, \& Hossain, 2020). This might be a neutral result of sudden shifts from actual face to face lecturing to virtual education. Nevertheless, these psychological issues to some extend hinder learners from adapting to virtual education (Chakraborty, Arora, \& Gupta, 2020). In fact, although of the training efforts by universities, students are different in terms of access equality, expertise, and digital technologies skills. Although these inequalities existed earlier, the COVID-19 pandemic has exposed this digital divide (Jæger \& Blaabæk, 2020). Perhaps, it was not easy shifting all the academic activities to online platform rapidly. The situation was assumed that will normalize shortly and the universities campuses could be reopened in very nearest days.

Universities as a temporary measure, has advised and professors students to continue teaching throughout the provided online portals and sources. However, technology and online learning were in all discussed scenarios advantage a major role for technology and online learning. Massive open online courses (MOOCs) and else techniques and teaching styles were the most recent candidates being pushed forward to fulfill these ambitious goals in regard to the distance education during the pandemic. 
Meanwhile, institutions strategized their teaching-learning processes, and academic activities were shifted to an online platform, albeit with certain changes. Instructors and students at the institution ultimately acclimated to the circumstance. Professors use Google Classroom, Zoom, Microsoft Teams, the global teaching platform BigBlueButton and other applications and platforms to deliver course materials and information as well as live lectures. Professors regularly use presentation software like PowerPoint and Prezi, as well as note-taking tools like OneNote, to deliver information. Depending on the nature of their lectures, professors may also use online tools to assist with problem solving, programming, and assignment creation.

Using empirical investigations in India, researchers attempted to explore students' perspectives on online education during the COVID-19 epidemic (Mishra, Gupta, \& Shree, 2020), and in Serbia (Bojovic, Bojovic, Vujosevic, \& Suh, 2020), and in USA (Aguilera-Hermida, 2020).

Irrefutable, the pandemic and the ensuing lockdowns have had an impact on people's health all across the world. Many students were suffering from stress and anxiety (Cao et al., 2020; Islam, Barna, Raihan, Khan, \& Hossain, 2020). Students' ability to adjust to online education is sometimes hampered by psychological difficulties. Furthermore, not all students have the same level of access to and knowledge of digital technology. Although these inequities existed before the COVID-19 pandemic, the COVID-19 pandemic has brought and exposed this digital gap to light.

Despite Bahrain universities' well-structured and good infrastructure in terms of technology and online platforms prior to and during the COVID-19 pandemic, the Ministry of Education in the Kingdom of Bahrain imposed a lockdown for students in all schools and higher education institutions to control the pandemic's spread and new operational strategy for educational institutions under the COVID-19 Alert Level Traffic Light System was announced (Ministry of Health, 2021). The universities' academic offerings are centered on intensive classroom and laboratory activity. It was challenging to instantly shift all of these academic activities into online platform. Furthermore, it was expected that the situation would quickly stabilize, and that the campuses would reopen within weeks.

Professors also employ online tools to help problem solving, programming, and creating tasks, depending on the nature of the courses. Professors use computers to offer lectures, which are frequently supplemented with a digital pen for instance and other necessary equipment.

During the COVID-19 outbreak, undergraduate students at several Bahraini universities were surveyed to find out what they felt about online education. The students' opinions on material delivery and participation in online education, as well as the health and social repercussions of online learning, were of particular interest to the current research.

\subsection{Online Education Strategies}

Various organizations were compelled to change their workflow methods and 
embrace new technology as a result of the epidemic. In most cases, these organizations did not have enough time to consider how new strategies and technology should be implemented and incorporated into their current operations (Carroll \& Conboy, 2020).

There were no exception all universities across the world were subject to this change. Because of the spreading epidemic, Bao (2020) may have been the first to explain how colleges were transitioning from classroom-based to online education. Using empirical investigations in India (Mishra, Gupta, \& Shree, 2020), Serbia (Bojovic, Bojovic, Vujosevic, \& Suh, 2020), and the United States, researchers attempted to explore students' perspectives on online education during the COVID-19 epidemic (Aguilera-Hermida, 2020).

Many nations had considerable online education infrastructure before to the epidemic (Mishra et al., 2020). No university, on the other hand, was prepared for a total move to online learning. Students believe they learn better in real classrooms than they do online, according to empirical studies (Bojovic et al., 2020). Students lose peer assistance in classes and laboratories, as well as access to the library (Aguilera-Hermida, 2020). Students, on the other hand, believe that online education enabled them to complete their studies during the epidemic (Mishra et al., 2020). Universities are now employing innovative ways to ensure that their students receive a continuous education (Zhu \& Liu, 2020).

Professors are increasingly using a variety of venues to provide course information. Professors are teaching their classes utilizing online educational platforms, video-conferencing software, and social media (Aguilera-Hermida, 2020). Professors can exchange notes and multimedia resources relevant to their courses with students using online educational platforms like Google Classroom and Blackboard. Students can turn in assignments and teachers can keep track of their students' progress using online educational platforms. Google Meet, Zoom, and Microsoft Teams are video conferencing applications that aid in the organization of online lectures and discussion sessions.

Slideshows and a chat box are common features of such programs. University websites (Chatterjee \& Chakraborty, 2020) and their own learning management systems are also used to disseminate course materials (Mishra et al., 2020). In addition, virtual laboratories are being used by instructors to teach science courses (Ray \& Srivastava, 2020). Students can use virtual laboratories to simulate experiments relevant to their studies online (Diaz \& Walsh, 2021; Vasiliadou, 2020). For many years, such tools were utilized for simulation and data visualization (Jain, Chakraborty, \& Chakraverty, 2018), but their usage has recently extended widely.

There are few research on how successful online assessment approaches are and how effectively students may engage with professors and fellow students using various online technologies. Only a few studies have looked into these topics. Students prefer face-to-face connection with instructors, according to Aguilera-Hermida (2020), while many professors lack trust in online evaluation procedures (Bojovic et al., 2020). 


\subsection{Health and Social Issues}

This period of time has witnessed several issues related to the COVID-19 pandemic, in academic life, some of the students' health has been impacted by the COVID-19 epidemic and the closure of university campuses (Savage et al., 2020).

According to empirical studies conducted in countries like Bangladesh (Khan et al., 2020), China (Li et al., 2021), France (Essadek \& Rabeyron, 2020), Greece (Kaparounaki et al., 2020), the United Kingdom (Savage et al., 2020), and the United States (Copeland et al., 2021), a large percentage of students suffer from mental disorders of varying severity. Many students expressed sadness, anxiety, discomfort, and even suicidal thoughts (Essadek \& Rabeyron, 2020), and even suicidal thoughts (Kaparounaki et al., 2020). The current scenario has a minor but lasting impact on pupils' mental health (Copeland et al., 2021). Students are concerned about the epidemic in general as well as their future professions (Hasan \& Bao, 2020). Many students find it challenging to focus on online education due to a lack of desire and bad emotions (Aguilera-Hermida, 2020).

According to Lembani, Gunter, Breines, and Dalu (2020), there is a digital gap between urban and rural regions, with rural pupils frequently lacking appropriate access to information and communication technologies. Economically deprived persons and those living in rural regions have restricted access to digital technology (Grishchenko, 2020). Online education requires consistent access to digital tools. Those students with limited access to digital technology, as well as those who are unfamiliar with technology, will always have difficulty adjusting to online education. The digital divide existed before the pandemic, but it was worsened by it (Beaunoyer, Dupéré, and Guitton, 2020). Furthermore, some students live in cramped quarters and have difficulty attending online classes from their homes (Aguilera-Hermida, 2020).

\section{Methodology}

The study employed quantitative method as the proper approach to achieve its objective. The main study tool was survey questionnaire which was adopted from three different prior studies (Raja \& Kallarakal, 2020). As an appropriate method to achieving the study aim, a questionnaire survey was conducted among a population of undergraduate and post-graduate students studying in Bahrain universities.

The sample size of this study's drawn from Bahraini universities' population sampling frames. About nineteen public and private universities were chosen from this directory (Bahrain Ministry of Education, 2021). About 35,000 students were identified as qualified because they met the criteria specified. Krejcie and Morgan's (1970), sample size determination table was used to choose a sample size for a population students. For a population of around 35,000 students, the table indicated that 655 sample sizes would be necessary $5.0 \%$ margin of error, greater confidence desired (0.05).

We used proportionate stratified and systematic samplings techniques, 400 
completed questionnaires were obtained through an online survey in about three months after the questionnaires were distributed to the respondents, which were considered as early answers that were utilized to analyze non-response bias on the real variables. To increase the response rate, a follow-up series of Short Message Service (SMS), messages via social media platforms such as WhatsApp to remind the students who had not yet returned their surveys. When compared to the initial answer, this effort generated the most responses. A total of 450 surveys were completed and returned. Late replies were labeled as such, and they were later utilized to assess the non-response bias.

A total of 420 questionnaires were returned from the 655 distributed questionnaires that were emailed to the respondents; of these, 5 were not usable due to excessive missing data, 7 were completely eliminated due to incorrect filling in of some items and option selection. As a result, the response rate was determined to be $64.2 \%$ percent, which is adequate for the research (Sekaran \& Bougie, 2019). During early analysis, 29 out of 449 usable surveys were eliminated because they were identified as multivariate outliers.

\subsection{Questionnaire Design and Development}

In order to achieve the study objectives, and for the purpose of gathering the required data, a total questionnaire of 20 statements about online education during the COVID-19 epidemic was created. Each sentence required to answer each statement by reply on a 5-point Likert scale, with 1 representing "Strongly disagree" and 5 representing "Strongly agree." The remarks were on the teachinglearning process in general, material delivery, professor-student interaction, assessment, and the impact of online education on health and social issues.

The participants were invited to compare and contrast online and traditional classroom instruction. We asked them if they believe professors' online teaching skills have improved since the outbreak and if online education is a feasible alternative in the current situation. We wanted to determine if students thought there were enough online resources accessible today, and if slideshows, note-taking applications, and more specialized online tools for problem-solving, programming, and designing might be added to the courses. We wanted to find out how the students felt about their online interactions with the lecturer.

The impact on students' health and social lives during the pandemic (online education) was one of the main objectives which we were looking into, therefore, several statements in this regard were created and distributed to the participators.

Also, the students were asked if they thought professor-student connection was enhanced when the professor used a teaching aids tools such as digital pen, and how the professor enabled students to submit messages in the chat-box for instance during lectures. Furthermore, the students were questioned if they thought online examinations and courses assessments (tests and quizzes etc.) could successfully evaluate their knowledge and if they thought weekly assign- 
ments and exams helped them learn. In addition, the abuse of digital technology was also one of the researcher's concerns. Furthermore, the study inquired if excessive screen usage causes students worry or interferes with their sleep. The students' evaluation anxiety between the two methods online and traditional modes of testing was subject to be tested in our study. Finally, the students were questioned if online education had an impact on their everyday lives, revealing the digital divide between them. Out of 655 questionnaires to university students on $15^{\text {th }}$ of 2020 till $30^{\text {th }}$ of Aug. 2021; 420 questionnaires usable returned presenting $64.1 \%$ which is acceptable rate in such situation more than $10 \%$ of population.

\subsection{Data Analysis}

The connection and covariance between several features of online education during the pandemic were investigated. The study investigated the impact of various variables of online education on social concerns connected to online education. On the other hand, in order to test and investigated this impact, SPSS (version 22) utilized. The assessment was carried out in two stages. The first stage was to determine the reliability and validity of the variables, or constructs. The demographic information regarding the participation was a satisfactory result.

\section{Results}

\section{Descriptive Results}

The total responses usable data after required data screening was 420 questionnaires who responded to the study survey reporting $64.1 \%$ of the response rate. The responders' average age was from 31 - 36 years $85.7 \%$ then 21 - 25 years old with $54.8 \%$ where ages of 18 - 20 responded with $14.3 \%$ lowest responded. However, $57.1 \%$ percent of the responders were female with 240 responders, while 180 responders $42.9 \%$ were male. During the COVID-19 epidemic, students had varied feelings about online education. Table 1 was created for better understanding of respond demographics by gender.

Based on the descriptive analysis of the study as showed in above Figure 1 and Table 1 and Table 2, 16.7\% of the students were strongly agreed that learning takes place better in physical classrooms than through online education, where $33 \%$ of the students were impartial in reply to this item, and $28.6 \%$ appeared to be strongly agreed that learning is better in physical classrooms than through online education. The total response of this items come from female responses with 240 responses in return 180 male responses. While the participants are impartial or agreed regarding to the professor if they allows the students to post comments in the chat box during a lecture, then it becomes interactive. However, the participant's answers were varying and different regarding respondents' opinions on a topic whether online education was a viable alternative during the COVID-19 pandemic times, $26.2 \%$ were strongly agree, $26.2 \%$ impartial 
Table 1. Responder's demographics by gender.

\begin{tabular}{cccccc}
\hline & & Frequency & Percent & Valid Percent & Cumulative Percent \\
\hline \multirow{3}{*}{ Valid } & Male & 240 & 57.1 & 57.1 & 57.1 \\
& Female & 180 & 42.9 & 42.9 & 100.0 \\
& Total & 420 & 100.0 & 100.0 & \\
\hline
\end{tabular}

Table 2. Responder's demographics by age.

\begin{tabular}{cccccc}
\hline & & Frequency & Percent & Valid Percent & Cumulative Percent \\
\hline & $18-20$ & 60 & 14.3 & 14.3 & 14.3 \\
$21-25$ & 90 & 21.4 & 21.4 & 35.7 \\
& $26-30$ & 80 & 19.0 & 19.0 & 54.8 \\
Valid & $36-31$ & 130 & 31.0 & 31.0 & 85.7 \\
& $37-40$ & 30 & 7.1 & 7.1 & 92.9 \\
& 40 and above & 30 & 7.1 & 7.1 & 100.0 \\
& Total & 420 & 100.0 & 100.0 &
\end{tabular}

\section{DESCRIPTIVE ANALSYS}

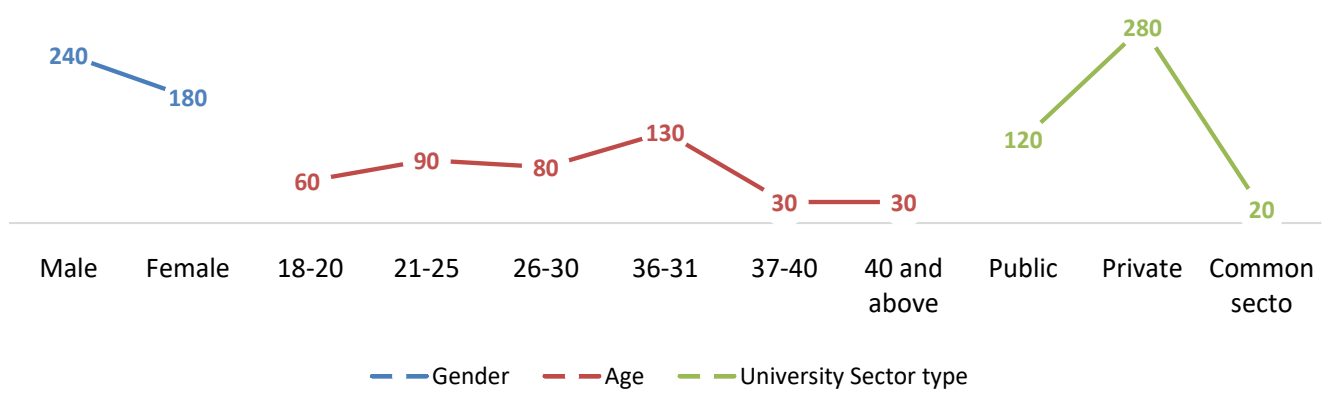

Figure 1. Descriptive analysis by responder's demographics.

where $31.0 \%$ strongly disagree. The majority of the student's (28.6\%) believed that Adequate study materials are available online which can be due to the well infrastructure preparation by the universities.

\section{Discussion and Conclusion}

With the recent attention in the education literature to teaching methods issues either face to face or online education approach or all the new approaches to education with a different focus on the main dimensions of online teaching for instance, the teaching methods and assessment is still under great debates by the researchers and diction making. In response, and in search of a new teaching method, prior research investigated the recent and previous related issues related to online education. However, so far and according to our knowledge, this work has not yet produced an overarching framework or typology that could help researchers to define and distinguish online education approach in terms of a final purpose. 
Nevertheless, the increasing number of publications on online education necessitated a more systematic look at the literature to better define and delineate the boundaries between the different approaches traditional and online education (Greenhow \& Galvin, 2020). Also, this literature needed a typology to guide future conceptual and empirical research. For a long time, the online education has been on the outskirts of society. The COVID-19 epidemic was well publicized. During the COVID-19 epidemic, we conducted a poll to find out what undergraduate students at an Indian institution thought about various elements of online education. We discovered that given the current conditions, pupils thought online education was a realistic option. However, we believe there is room for development. Professors should work to improve student acceptance of online education. Techniques such as flipped classrooms, case studies, and gamification might be used in online education and its impacts could be investigated. For the first time, the COVID-19 epidemic has resulted in widespread acceptance of online education throughout the world. The lessons we've learned about online education as a result of this epidemic will come in handy in the future (Chatterjee \& Chakraborty, 2020; Skulmowski \& Rey, 2020).

However, it worth to mention that by examining the potential digitalization of legal education, keep in mind that it is not just about using digital technology in education, it is also about changing the content of legal education as a result of the legal terms and conditions of digital revolution today (Osina, Tolstopyatenko, \& Malinovsky, 2020). Online education is allowing medical students to attend lectures and access study materials from anywhere and at any time using a computer or a smartphone (Chick et al., 2020). This is particularly helpful for international students many of whom have returned to their native countries at the outbreak of the pandemic (Sandhu \& de Wolf, 2020). Similar to other educational domains, usage of ICT tools has also brought about a democratization of educational content, giving students access to high-quality didactic tutorials by the pioneers in their field, regardless of geographical and monetary barriers (AbiRafeh \& Azzi, 2020).

However, although of the unexpected circumstances caused by the pandemic outbreak of coronavirus illness, and perhaps the collective efforts by the authorities and governments around the globe, where many lessons have been learned in our small world; such as sharing how to overcome the learning dilemma, etc. in several occasions, still work to be done. There are a lot of improvements required such as more engagements from the relevant authorities by putting in place more legislation and strict regulations in order to ensure the process and the effectiveness of virtual education. Governments should be able by now to solve some issues related to virtual education by setting the correct and good plans through will set risk management experts individuals and parties to look not only on the alternatives; but on the right solutions.

\section{Conflicts of Interest}

The author declares no conflicts of interest regarding the publication of this paper. 


\section{References}

Abi-Rafeh, J., \&Azzi, A. J. (2020). Emerging Role of Online Virtual Teaching Resources for Medical Student Education in Plastic Surgery: COVID-19 Pandemic and Beyond. Journal of Plastic, Reconstructive \& Aesthetic Surgery, 73, 1575. https://doi.org/10.1016/j.bjps.2020.05.085

Aguilera-Hermida, A. P. (2020). College Students' Use and Acceptance of Emergency Online Learning Due to COVID-19. International Journal of Educational Research Open, 1, Article ID: 100011. https://doi.org/10.1016/j.ijedro.2020.100011

Bahrain Ministry of Education (2021). List of Universities in Bahrain. https://www.mofa.gov.bh/Default.aspx?tabid=10813\&language $=$ ar-BH

Bao, W. (2020). COVID-19 and Online Teaching in Higher Education: A Case Study of Peking University. Human Behavior and Emerging Technologies, 2, 113-115. https://doi.org/10.1002/hbe2.191

Beaunoyer, E., Dupéré, S., \& Guitton, M. J. (2020). COVID-19 and Digital Inequalities: Reciprocal Impacts and Mitigation Strategies. Computers in Human Behavior, 111, 106424. https://doi.org/10.1016/j.chb.2020.106424

Bojovic, Ž., Bojović, P. D., Vujošević, D., \& Šuh, J. (2020). Education in Times of Crisis: Rapid Transition to Distance Learning. Computer Applications in Engineering Education, 28, 1467-1489. https://doi.org/10.1002/cae.22318

Cao, W., Fang, Z., Hou, G., Han, M., Xu, X., Dong, J., \& Zheng, J. (2020). The Psychological Impact of the COVID-19 Epidemic on College Students in China. Psychiatry Research, 287, Article ID: 112934. https://doi.org/10.1016/j.psychres.2020.112934

Carroll, N., \& Conboy, K. (2020). Normalising the "New Normal”: Changing Tech-Driven Work Practices under Pandemic Time Pressure. International Journal of Information Management, 55, Article ID: 102186. https://doi.org/10.1016/j.ijinfomgt.2020.102186

Chakraborty, P., Arora, A., \& Gupta, M. S. (2020). Opinion of Students on Online Education during the COVID-19 Pandemic. Human Behaviour and Emerging Technology, 3, 357-365. https://doi.org/10.1002/hbe2.240

Chatterjee, I., \& Chakraborty, P. (2020). Use of Information and Communication Technology by Medical Educators amid COVID-19 Pandemic and Beyond. Journal of Educational Technology Systems, 49, 310-324. https://doi.org/10.1177/0047239520966996

Chick, R. C., Clifton, G. T., Peace, K. M., Propper, B. W., Hale, D. F., Alseidi, A. A., \& Vreeland, T. J. (2020). Using Technology to Maintain the Education of Residents during the COVID-19 Pandemic. Journal of Surgical Education, 77, 729-732.

https://doi.org/10.1016/j.jsurg.2020.03.018

Copeland, W. E., McGinnis, E., Bai, Y., Adams, Z., Nardone, H., Devadanam, V., Hudziak, J. J. et al. (2021). Impact of COVID-19 Pandemic on College Student Mental Health and Wellness. Journal of the American Academy of Child \& Adolescent Psychiatry, 60, 134-141. https://doi.org/10.1016/j.jaac.2020.08.466

de Regt, A. et al. (2020). The Virtual Reality Chain. Business Horizons, 63, 737-748. https://doi.org/10.1016/j.bushor.2020.08.002

Dhawan, S. (2020). Online Learning: A Panacea in the Time of COVID-19 Crisis. Journal of Educational Technology Systems, 49, 5-22. https://doi.org/10.1177/0047239520934018

Diaz, M. C. G., \& Walsh, B. M. (2021). Telesimulation-Based Education during COVID-19. The Clinical Teacher, 18, 121-125. https://doi.org/10.1111/tct.13273

Essadek, A., \& Rabeyron, T. (2020). Mental Health of French Students during the COVID19 Pandemic. Journal of Affective Disorders, 277, 392-393. 
https://doi.org/10.1016/j.jad.2020.08.042

Gandhi, S., Srivastava, A. K., Ray, U., \& Tripathi, P. P. (2020). Is the Collapse of the Respiratory Center in the Brain Responsible for Respiratory Breakdown in COVID-19 Patients? ACS Chemical Neuroscience, 11, 1379-1381.

https://doi.org/10.1021/acschemneuro.0c00217

Graham, C. R. (2013). Emerging Practice and Research in Blended Learning. In Handbook of Distance Education (3rd ed., pp. 333-350). Routledge. https://doi.org/10.4324/9780203803738.ch21

Greenhow, C., \& Galvin, S. (2020). Teaching with Social Media: Evidence-Based Strategies for Making Remote Higher Education Less Remote. Information and Learning Sciences, 121, 513-524. https://doi.org/10.1108/ILS-04-2020-0138

Grishchenko, N. (2020). The Gap Not Only Closes: Resistance and Reverse Shifts in the Digital Divide in Russia. Telecommunications Policy, 44, Article ID: 102004. https://doi.org/10.1016/j.telpol.2020.102004

Hasan, N., \& Bao, Y. (2020). Impact of “e-Learning Crack-Up” Perception on Psychological Distress among College Students during COVID-19 Pandemic: A Mediating Role of "Fear of Academic Year Loss". Children and Youth Services Review, 118, Article ID: 105355. https://doi.org/10.1016/j.childyouth.2020.105355

Islam, M. A., Barna, S. D., Raihan, H., Khan, M. N. A., \& Hossain, M. T. (2020). Depression and Anxiety among University Students during the COVID-19 Pandemic in Bangladesh: A Web-Based Cross-Sectional Survey. PLoS ONE, 15, e0238162. https://doi.org/10.1371/journal.pone.0238162

Jæger, M. M., \& Blaabæk, E. H. (2020). Inequality in Learning Opportunities during Covid-19: Evidence from Library Takeout. Research in Social Stratification and Mobility, 68, Article ID: 100524. https://doi.org/10.1016/j.rssm.2020.100524

Jain, D., Chakraborty, P., \& Chakraverty, S. (2018). Smartphone Apps for Teaching Engineering Courses: Experience and Scope. Journal of Educational Technology Systems, 47, 4-16. https://doi.org/10.1177/0047239518785166

Khan, A. H., Sultana, M. S., Hossain, S., Hasan, M. T., Ahmed, H. U., \& Sikder, M. T. (2020). The Impact of COVID-19 Pandemic on Mental Health \& Wellbeing among Home-Quarantined Bangladeshi students: A Cross-Sectional Pilot Study. Journal of Affective Disorders, 277, 121-128. https://doi.org/10.1016/j.jad.2020.07.135

Krejcie, R. V., \& Morgan, D. W. (1970). Determining Sample Size for Research Activities. Educational and Psychological Measurement, 30, 607-610. https://doi.org/10.1177/001316447003000308

Lembani, R., Gunter, A., Breines, M., \& Dalu, M. T. B. (2020). The Same Course, Different Access: The Digital Divide between Urban and Rural Distance Education Students in South Africa. Journal of Geography in Higher Education, 44, 70-84. https://doi.org/10.1080/03098265.2019.1694876

Li, Y. C., Wang, Y., Jiang, J. W., Valdimarsdóttir, U. A., Fall, K., Fang, F., Song, H., Lu, D. H., \& Zhang, W. (2021). Psychological Distress among Health Professional Students during the COVID-19 Outbreak. Psychological Medicine, 51, 1952-1954.

https://doi.org/10.1017/S0033291720001555

Ministry of Health (2021). Bahrain's Ministry of Education Announces the Operational Strategy for Educational Institutions under the COVID-19 Alert Level Traffic Light System. https://healthalert.gov.bh/en/article/News-139756

Mishra, L., Gupta, T., \& Shree, A. (2020). Online Teaching-Learning in Higher Education during Lockdown Period of COVID-19 Pandemic. International Journal of Educational Research Open, 1, Article ID: 100012. https://doi.org/10.1016/j.ijedro.2020.100012 
Nash, C. (2020). Report on Digital Literacy in Academic Meetings during the 2020 COVID19 Lockdown. Challenges, 11, 20. https://doi.org/10.3390/challe11020020

Osina, D. M., Tolstopyatenko, G. P., \& Malinovsky, A. A. (2020). Digitalization of Higher Legal Education in Russia in the Age of Covid-19. In International Scientific and Practical Conference (pp. 392-398). Springer.

https://doi.org/10.1007/978-3-030-53277-2 47

Patsali, M. E., Mousa, D. P. V., Papadopoulou, E. V., Papadopoulou, K. K., Kaparounaki, C. K., Diakogiannis, I., \& Fountoulakis, K. N. (2020). University Students' Changes in Mental Health Status and Determinants of Behavior during the COVID-19 Lockdown in Greece. Psychiatry Research, 292, 113298.

https://doi.org/10.1016/j.psychres.2020.113298

Raja, M. A. S., \& Kallarakal, T. K. (2020). “COVID-19 and Students Perception about MOOCs" a Case of Indian Higher Educational Institutions. Interactive Technology and Smart Education, 18, 450-474.

Ray, S., \& Srivastava, S. (2020). Virtualization of Science Education: A Lesson from the COVID-19 Pandemic. Journal of Proteins and Proteomics, 11, 77-80.

Sandhu, P., \& de Wolf, M. (2020). The Impact of COVID-19 on the Undergraduate Medical Curriculum. Medical Education Online, 25, Article ID: 1764740. https://doi.org/10.1080/10872981.2020.1764740

Savage, M. J., James, R., Magistro, D., Donaldson, J., Healy, L. C., Nevill, M., \& Hennis, P. J. (2020). Mental Health and Movement Behaviour during the COVID-19 Pandemic in UK University Students: Prospective Cohort Study. Mental Health and Physical Activity, 19, Article ID: 100357. https://doi.org/10.1016/j.mhpa.2020.100357

Sekaran, U., \& Bougie, R. (2019). Research Methods for Business: A Skill Building Approach. John Wiley \& Sons.

Skulmowski, A., \& Rey, G. D. (2020). COVID-19 as an Accelerator for Digitalization at a German University: Establishing Hybrid Campuses in Times of Crisis. Human Behavior and Emerging Technologies, 2, 212-216. https://doi.org/10.1002/hbe2.201

Vasiliadou, R. (2020). Virtual Laboratories during Coronavirus (COVID-19) Pandemic. Biochemistry and Molecular Biology Education, 48, 482-483.

https://doi.org/10.1002/bmb.21407

Yan, Z. (2020). Unprecedented Pandemic, Unprecedented Shift, and Unprecedented Opportunity. Human Behavior and Emerging Technologies, 2, 110-112.

Zhu, X., \& Liu, J. (2020). Education in and after Covid-19: Immediate Responses and Long-Term Visions. Postdigital Science and Education, 2, 695-699.

https://doi.org/10.1007/s42438-020-00126-3 